\title{
Sleep disturbance in movement disorders: insights, treatments and challenges
}

\author{
Grace A Bailey (1) , ${ }^{1}$ Emily K Hubbard, ${ }^{2}$ Alfonso Fasano, ${ }^{3,4,5}$ Marina AJ Tijssen (1) , ${ }^{6}$ \\ Timothy Lynch, ${ }^{7}$ Kirstie N Anderson, ${ }^{8}$ Kathryn J Peall (1) ${ }^{1}$
}

- Prepublication history and additional material is published online only. To view please visit the journal online (http://dx.doi.org/10.1136/ jnnp-2020-325546)

${ }^{1}$ Neuroscience and Mental Health Research Institute, Cardiff University, Cardiff, UK ${ }^{2}$ School of Medicine, Cardiff University, Cardiff, UK ${ }^{3}$ Edmond I Safra Program in Parkinson's Disease, Morton and Gloria Shulman Movement Disorders Clinic, Toronto Western Hospital, Toronto, Ontario, Canada

${ }^{4}$ Division of Neurology, University of Toronto, Toronto, Ontario, Canada

${ }^{5}$ Krembil Research Institute, Toronto, Ontario, Canada ${ }^{6}$ Department of Neurology, University Medical Centre Groningen, Groningen, The Netherlands

${ }^{7}$ Dublin Neurological Institute, The Mater Misericordiae University Hospital, Dublin, Dublin, Ireland

${ }^{8}$ Department of Neurology, Newcastle Upon Tyne Hospitals NHS Foundation Trust, Newcastle Upon Tyne, UK

Correspondence to Dr Kathryn J Peall, Neuroscience and Mental Health Research Institute, Cardiff University, Cardiff CF24 4HQ, UK; PeallKJ@ cardiff.ac.uk

Received 3 November 2020 Revised 7 January 2021 Accepted 1 February 2021 Published Online First 19 March 2021

Check for updates

(C) Author(s) (or their employer(s)) 2021. No commercial re-use. See rights and permissions. Published by BMJ.

To cite: Bailey GA, Hubbard EK, Fasano A, et al. J Neurol Neurosurg Psychiatry

2021:92:723-736

\section{ABSTRACT}

Sleep and circadian rhythm disturbances are central features of many movement disorders, exacerbating motor and non-motor symptoms and impairing quality of life. Understanding these disturbances to sleep is clinically important and may further our understanding of the underlying movement disorder. This review evaluates the current anatomical and neurochemical understanding of normal sleep and the recognised primary sleep disorders. In addition, we undertook a systematic review of the evidence for disruption to sleep across multiple movement disorders. Rapid eye movement sleep behaviour disorder has emerged as the most reliable prodromal biomarker for the alpha synucleinopathies, including Parkinson's disease and multiple system atrophy, often preceding motor symptom onset by several years. Abnormal sleep has also been described for many other movement disorders, but further evidence is needed to determine whether this is a primary or secondary phenotypic component of the underlying condition. Medication used in the treatment of motor symptoms also affects sleep and can aggravate or cause certain sleep disorders. Within the context of movement disorders, there is also some suggestion of a shared underlying mechanism for motor and sleep pathophysiology, with evidence implicating thalamic and brainstem structures and monoaminergic neurotransmission. This review highlights the need for an understanding of normal and abnormal sleep within the movement disorder clinic, an ability to screen for specific causes of poor sleep and to treat sleep disturbance to improve quality of life. Key sleep disorders also act as important biomarkers and have implications in diagnosis, prognosis and the development of future therapies.

\section{INTRODUCTION}

Abnormal sleep and circadian rhythm disorders are seen in many patients with movement disorders, although they remain underdiagnosed and are a significant unmet need in clinical care. Sleep and circadian rhythms are generated from specific regulatory centres, including the forebrain, thalamus and midbrain dopaminergic neurons, regions also implicated in movement disorder pathogenesis.

The rate, nature and temporal pattern of these sleep disturbances vary across the different movement disorders. For example, in Parkinson's disease (PD) the rate of sleep disorders has been estimated to be as high as $98 \%$, with rapid eye movement (REM) sleep behaviour disorder well established as predating motor symptom onset. $^{1}$ In contrast, those such as adult-onset primary, idiopathic dystonia, may have poor sleep with evidence suggesting a link to psychiatric symptom severity. ${ }^{2}$

This review provides an overview of the common sleep disorders and the evidence to date for the patterns and prevalence across a spectrum of movement disorders. We discuss the tools available for sleep assessment, the impact of medication used in motor symptom management on sleep, and how disturbed sleep can affect daytime motor function. Finally, we highlight future challenges to the field, and general considerations in the assessment and treatment of sleep disorders in patients diagnosed with a movement disorder.

\section{Sleep structure, anatomy and physiology}

Sleep cycles approximately every 90-120 min between an initial non-REM (NREM) stage (subdivided into N1-3 stages), followed by a $\mathrm{REM} / \mathrm{R}$ phase with a relative muscle atonia. Figure 1 summarises the typical hypnogram, although with normal ageing, night awakenings increase, N3 decreases and total sleep time shortens.

Maintenance of the sleep/wake circuit is regulated by the fast-acting neurotransmitters glutamate and gamma aminobutyric acid (GABA), while an array of excitatory neurotransmitters are thought to have a modulatory role, including hypocretin/orexin (lateral hypothalamus, LH), histamine (tuberomammillary nucleus), acetylcholine (pedunculopontine (PPT) and laterodorsal tegmentum), norepinephrine (locus coeruleus), dopamine (ventral periaqueductal grey (vPAG) matter) and serotonin (raphe nuclei) (figure $2 \mathrm{~A}-\mathrm{C}$ ). Sleep regulatory circuits are widespread throughout the brainstem and hypothalamus. GABAergic parvalbumin neurons in the basal forebrain arousal system and GABAergic neurons in the parafacial zone of the medulla are essential for driving wakefulness, with the latter promoting sleep via inhibition of glutamatergic neurons in the parabrachial nucleus (PB). More recently, evidence suggests that GABAergic neurons in the LH contribute to promoting wakefulness by inhibiting the thalamus and preoptic area. The ventrolateral preoptic area also contains GABAergic neurons, 


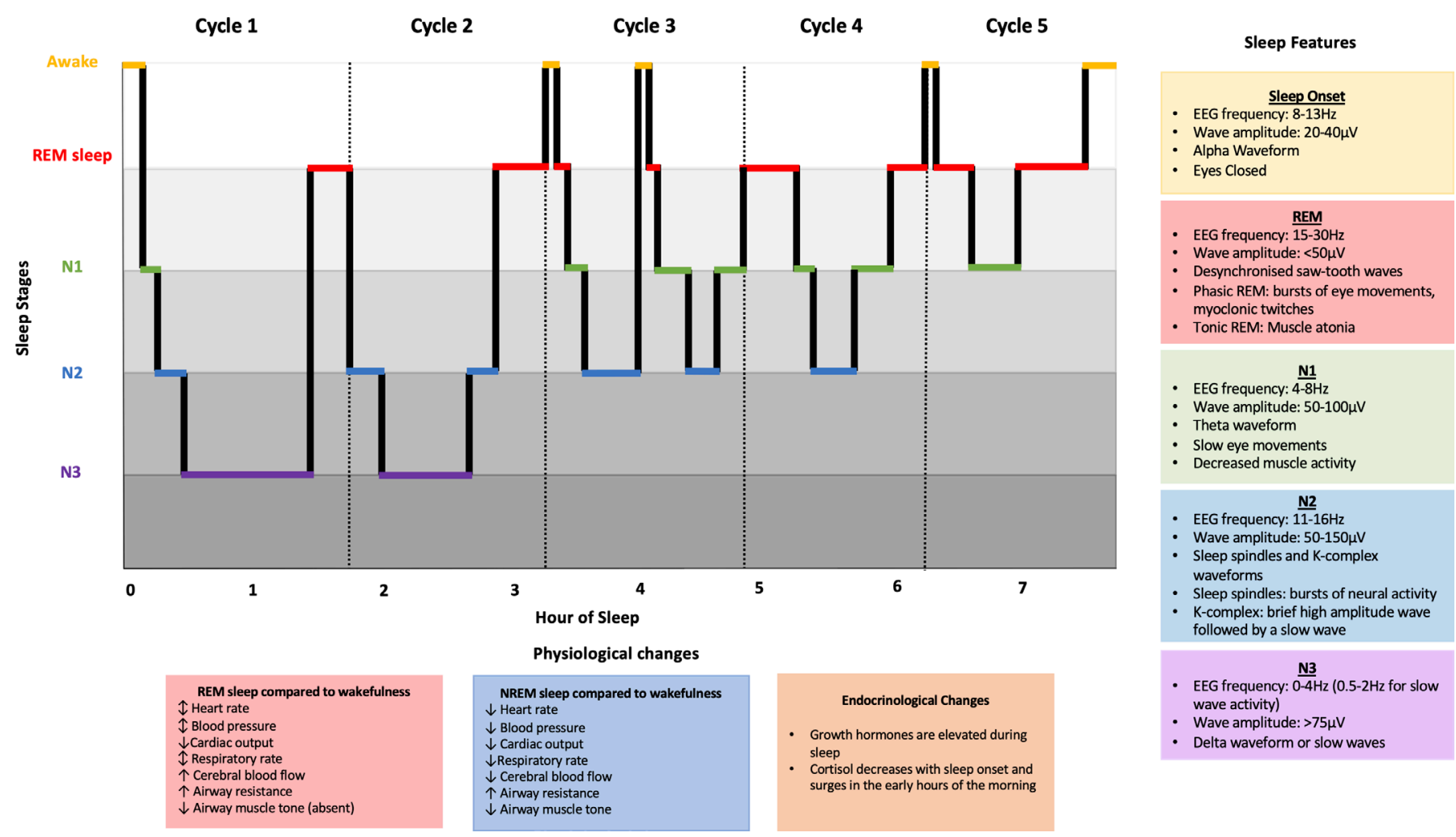

Figure 1 Sleep hypnogram illustrating a normal sleep cycle and physiological changes. NREM1/2/3: non-rapid eye movement sleep stages 1, 2 and 3, REM sleep: rapid eye movement. NREM, non-rapid eye movement.

essential for promoting sleep via inhibition of the arousal system.

Glutamatergic REM-promoting neurons in the sublaterodorsal nucleus (SLD) are inhibited by GABAergic NREMpromoting neurons in the vPAG, while activation of GABAergic neurons in the ventral medulla which innervate vPAG promotes transition to REM sleep by disinhibition of the SLD. NREM sleep is driven by GABAergic neurons in the vPAG and glutamatergic neurons located ventromedial to the superior cerebellar peduncle. These neurons suppress both wakefulness and REM sleep by inhibiting the SLD, with additional inhibition of the medial PB by GABAergic neurons also promoting NREM sleep. Newer models of the sleep/ wake circuit recognise that these interactions are modulated by several brain regions including the PPT, laterodorsal tegmental nuclei (LDT), projections from the medulla and the melanin-concentrating neuron system (figure $2 \mathrm{~A}, \mathrm{~B}) .^{3}$

\section{Types of sleep disorders}

The different forms of sleep disorders, as defined by the International Classification of Sleep Disorders, their clinical features, diagnostic criteria, proposed underlying pathophysiology and currently suggested treatments are summarised in table 1.

\section{Diagnosing sleep disorders}

Online supplemental table 1 summarises the available sleep questionnaires. Sleep diaries and wrist actigraphy are often used for the diagnosis of insomnia and circadian rhythm disorders as well as population screening in research cohorts. The gold standard for objective sleep staging remains in-patient video polysomnography (PSG), involving video, electroencephalography, electromyography and electrooculography.
PSG is required for confirming the diagnosis of REM Sleep Behavioural Disorder (RBD), while PSG and multiple sleep latency test (MSLT) are used in the diagnoses of narcolepsy and other central hypersomnias.

\section{Technology to aid diagnostic and therapeutic management} Development of consumer wearables is becoming recognised as a prospective clinical tool, aiding early diagnosis as well as the opportunity to monitor disease progression particularly, for example, in response to therapeutics. Actigraphy, an accelerometer validated to detect sleep/wake activity patterns, is particularly useful for documenting sleep-wake patterns for periods of days or weeks in the patient's own environment, as well as measuring physical activity during periods of wakefulness. Use of these wearable devices extends far beyond disease alone, potentially providing avenues to better understand the association between sleep and health, as well as opportunities to optimise interventions and reduce the adverse health impacts of poor sleep.

\section{Review of the evidence for sleep disturbance across} degenerative and non-degenerative movement disorders The literature search included the key words "sleep disturbances", "sleep disorders"; "RLS"; "PLMS"; "sleep related breathing disorders"; "RBD"; "excessive daytime sleepiness"; "insomnia" in combination with degenerative movement disorders: PD, Dementia with Lewy bodies (DLB), Multiple System Atrophy (MSA), Progressive Supranuclear Palsy (PSP), Corticobasal Syndrome (CBS), Huntington's Disease (HD), Dentatorubral-pallidoluysian Atrophy, spinocerebellar ataxia (SCA), Anti-immunoglobulin-like cell adhesion molecule 5 (IgLON5) disease, Wilson's Disease (WD), 


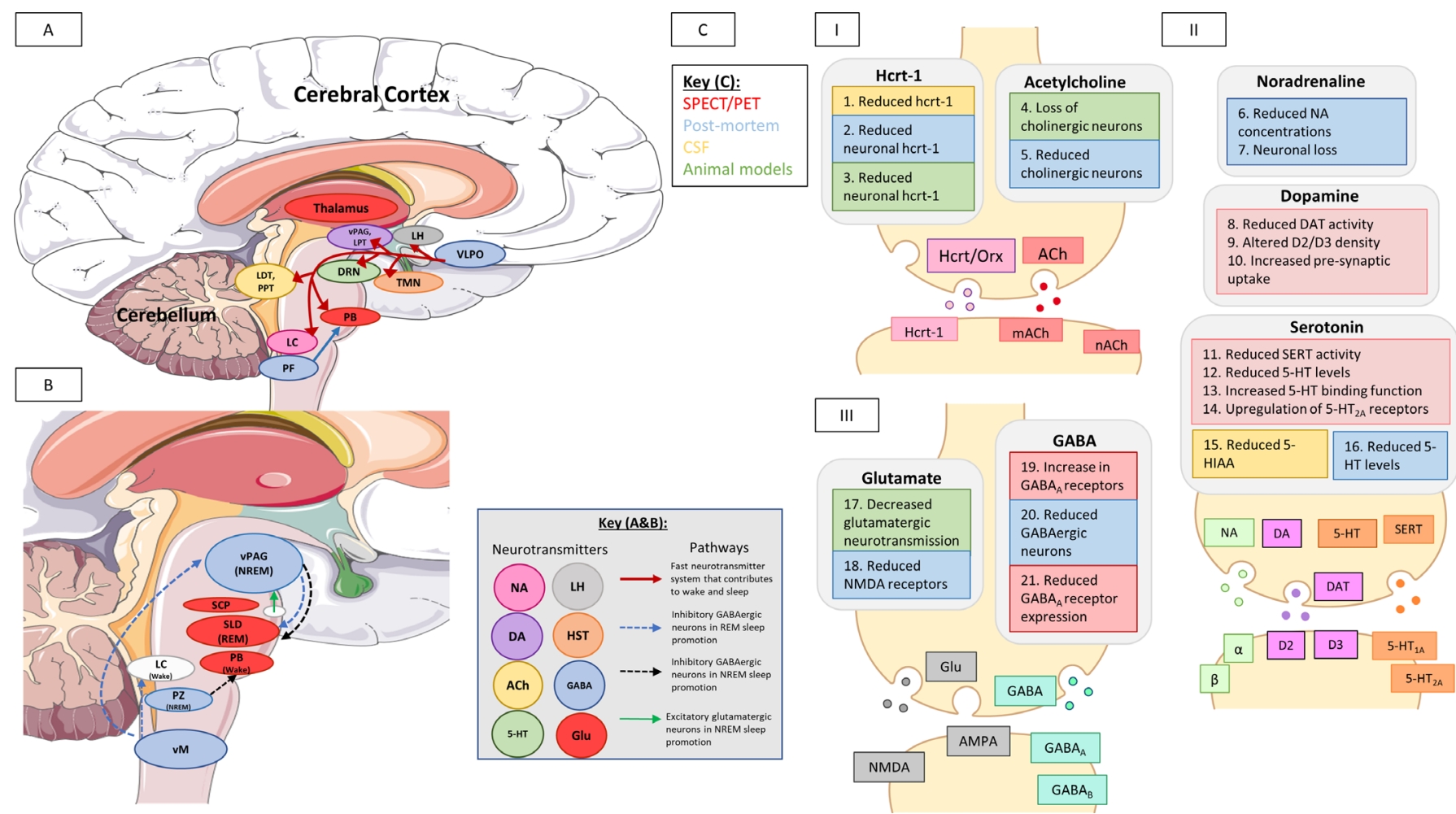

Figure 2 (A) Neurotransmitters and brain regions involved in the sleep-wake cycle (B) REM sleep circuitry: Hypothesised pathways include synucleinopathic degeneration in the SLD in DLB, in addition to Vm in PD, causing loss of REM sleep atonia and associated motor behaviours. Pathological changes to the LDT/PPN and LC in MSA may contribute to RBD. (C) Schematic of neurotransmitters involved in movement disorders in the context of sleep. (I) Hypocretin/orexin and acetylcholine: 1: reduced hrct-1 in the CSF of NPC, PSP and PD, 2: reduced immunostaining of hcrt-1 neurons in MSA and HD patients, 3: decreased hcrt-1 in mouse models of HD, 4: deletion of torsinA protein was associated with cholinergic neuronal loss in dystonia, 5: cholinergic neuronal loss in the striatum of PD and PSP patients. (II) Monoamines: 6: reduced Na concentrations in dystonia patients, 7: neuronal loss of Na neurons in $P D$, 8: reduced DAT in WD, NPC and Ts, and RBD patients who developed PD, 9: Reduced D3 receptors in PD associated with EDS, reduced D2 receptors in genetic carriers of DYT1, DYT6, DYT11 and NKX2.1, increased D2 receptors in TS, 10: Elevated DA uptake in TS, 11: Reduced SERT in PD, MSA and CD, 12: Reduced 5-HT levels in the DRN of CD patients, 13: increased 5-HT binding function in Ts patients, 14: Upregulation of 5-HT ${ }_{2 A}$ receptors in Ts cohorts, 15: reduced 5-HIAA in MD, 16: depleted 5-HT in raphe nuclei of MSA cases. (III) Glutamate and GABA: 17: reduced glutamatergic neurotransmission in animal mouse models of NPC, 18: reduced NMDA receptors in HD, 19: increase in GABA receptors in HTT gene carriers and et patients, 20: Reduced GABAergic neurons in TS brains, 21: Reduced GABA receptors in dystonia. AMPA: $\alpha$-amino-3-hydroxy-5-methyl-4-isoxazolepropionic acid receptor; BF, basal forebrain; D2/3, Dopamine receptors; DA, dopamine; DAT, dopamine transporter; DRN, dorsal raphe nuclei; GABA, gamma aminobutyric acid; Glu, glutamate; Hcrt/Orx, hypocretin/orexin; HIAA, 5-hydroxyindoleacetic acid; HIST, histamine; LC, locus coeruleus; LDT, lateral dorsal tegmentum; LPT, lateral pontine tegmentum; LH, lateral hypothalamus; $\mathrm{MCH}$, melanin-concentrating hormone; NA, norepinephrine; nACh, nicotinic acetylcholine receptors; NMDA, N-methyl-D-aspartate; $\mathrm{Pb}$, parabrachial nucleus; PPN, pedunculopontine nucleus; PPT, pedunculopontine; PZ, parafacial zone; SCP, superior cerebellar peduncle; SERT, serotonin transporter; SLD, sublaterodorsal nucleus; SN, substania nigra; TMN, tuberomammillary nucleus; VLPO, ventrolateral preoptic nucleus; vM, ventromedial Medulla; vPAG, ventral Periaqueductal grey matter; VTA, ventral tegmental area.

Niemann-Pick disease type C (NPC), Neurodegeneration with Brain Iron Accumulation (NBIA) including: pantothenate kinase-associated neurodegeneration, PLA2G6-associated neurodegeneration, beta-propeller protein-associated neurodegeneration, mitochondrial membrane protein-associated neurodegeneration and fatty acid hydroxylase-associated neurodegeneration, neuroacanthocytosis including: McLeod syndrome and Chorea-acanthocytosis and non-degenerative movement disorders: Dystonia, Essential Tremor (ET), Dystonic Tremor, Myoclonus (excluding myoclonus in relation to epilepsy), Tourette's syndrome (TS), Tic Disorders and Benign Hereditary Chorea (BHC). Studies identified were divided according to cohort size and methods of assessment (online supplemental tables 2-6). Only those involving PSG studies undertaken in case-control cohorts are discussed below and summarised in tables 2 and 3 . Where there is evidence, we have also sought to discuss potential underlying pathophysiological mechanisms.

\section{Parkinsonism}

Sleep disorders in PD

Sleep disturbance, which is typically multifactorial, is as high as 74\%-98\% in individuals diagnosed with PD, with well documented evidence of parasomnias including RBD, Periodic Limb Movements During Sleep (PLMS) and sleep related breathing disorders. Many sleep symptoms are related to disease duration, for example, there are increased disturbances to sleep architecture, insomnia and somnolence in later disease stages compared with earlier timepoints. Two recent review articles provide detailed oversight of the PSG findings and therapeutic management of sleep disturbance in PD, and therefore we have only provided a brief overview below. $^{45}$

RBD is well characterised in PD populations with longitudinal case-control studies identifying $73.5 \%$ of patients with idiopathic RBD (iRBD) develop a neurodegenerative 
Movement disorders

Table 1 Characteristic features of sleep disorders defined by the International Classification of Sleep Disorders

\begin{tabular}{|c|c|c|c|c|}
\hline Sleep disorder & Clinical features & Diagnostic criteria & Treatment & Proposed pathophysiology \\
\hline Chronic insomnia & $\begin{array}{l}\text { Difficulty falling asleep and/or maintaining } \\
\text { sleep, with symptoms impacting daytime } \\
\text { activity. Symptoms present on most nights } \\
\text { for at least } 3 \text { months and occur at least } \\
\text { three times per week. }\end{array}$ & $\begin{array}{l}\text { Problems initiating sleep, } \\
\text { difficulty maintaining sleep, } \\
\text { waking up earlier than } \\
\text { desired, resistance going to } \\
\text { bed on appropriate schedule } \\
\text { or difficulty sleeping without } \\
\text { parent/caregiver intervention. } \\
\text { Sleep/wake complaints cannot } \\
\text { be explained by inadequate } \\
\text { opportunity or circumstances. } \\
\text { In addition, fatigue, impaired } \\
\text { performance, prone to errors/ } \\
\text { accidents }\end{array}$ & $\begin{array}{l}\text { First Line: CBT where available. } \\
\text { Other treatments: } \\
\text { antihistamines, melatonin, } \\
\text { benzodiazepines }\end{array}$ & $\begin{array}{l}\text { 1. Disinhibition of the VPLO } \\
\text { 2. Impaired disengagement of } \\
\text { cortical regions involved in } \\
\text { executive control and attention } \\
\text { 3. REM instability } \\
\text { 4. Melatonin deficiency }\end{array}$ \\
\hline
\end{tabular}

Sleep-related breathing disorders

Obstructive sleep apnoea Chronic disorder characterised by snoring with episodes of upper airway collapse during sleep, waking with choking or breath holding. Associated fragmented, unrefreshing night sleep, insomnia and excessive daytime sleepiness. Risk factors: hypertension, type 2 diabetes mellitus and congestive cardiac failure.

Central sleep apnoea

Abnormal brainstem ventilatory responses leading to reduced or absent respiratory effort, with no evidence of snoring. Results in insufficient/absent ventilation, frequent night-time awakenings and excessive daytime sleepiness.

Common causes: opiate use and cardiac failure

Hypersomnolence Narcolepsy

Orexin/hypocretin-deficiency resulting in daytime sleepiness, sleep paralysis, hypnagogic hallucinations \pm cataplexy cause by instability in transitions between wake, NREM and REM sleep.
PSG detecting $\geq 5 /$ hour obstructive respiratory event alongside other criteria (eg, partners reports of habitual snoring or breath interruptions) or $\geq 15$ /hour obstructive respiratory events during PSG.

PSG demonstrating $\geq 5 /$ hour central apnoeas, number of central apnoeas is $>50 \%$ of the total number of apnoeic and hypopneic episodes
CPAP: recommended first-line therapy

1. Altered arousal threshold

2. Instability of ventilatory control

3. Increased glutamate and decreased GABA neurotransmission

4. Small pharyngeal airway

CPAP treatment is less effective than 1. Absence of ventilatory drive in OSA.

Narcolepsy Type 1: Diagnosed by Amphetamine-like, modafinil, sodium 1. Unstable transitions between the presence of one or both of oxybate wake, REM and NREM sleep caused by loss of hypocretin neurons latency of $\leq 8 \mathrm{~min}$ and (2) two or more sleep-onset REM periods (SOREMPs) on an MSLT. Narcolepsy Type 2: Daily periods of irrepressible need to sleep or daytime lapses into sleep confirmed with MSLT. Absence of cataplexy confirmed with CSF hypocretin-1 concentrations $(>110 \mathrm{pg} / \mathrm{mL}$ or $>1 / 3$ of mean values obtained in normal subjects).

Idiopathic hypersomnia Excessive daytime sleep and/or sleepiness, prolonged unrefreshing overnight sleep and difficulty waking occurring for at least 3 months.
MSLT shows fewer than two sleep-onset REM periods or $n$ if REM latency is $\leq 15 \mathrm{~min}$. In addition to the presence of either an MSLT of $\leq 8 \mathrm{~min}$, elevated total sleep time (12-14 hours) on PSG/wrist actigraphy or at least 3 daytime lapses into sleep associated with a sleep log (over seven nights).

Parasomnias

NREM parasomnias
Confusional arousal, somnambulism and sleep terrors with incomplete/no recall. Predominantly arise during the first third of the night, during slow wave sleep.
Confusional arousal: Recurrent mental confusion on arousal/ awakening, absence of fear, walking behaviour or hallucinations in association with episode.

Sleep walking: Ambulation during sleep, difficulty arousing the patient during an episode, amnesia.

Sleep terrors: PSG demonstrates tachycardia in associated with the episode and other sleep disorders for example, nightmares, can be present.
Medical therapy used when episodes 1. Reduced regional perfusion in are frequent or violent. Melatonin the frontal and parietal areas and benzodiazepines, notably clonazepam, most commonly used. 2. Activity in the thalamus and cingulate cortex during N3 sleep 
Table 1 Continued

\begin{tabular}{|c|c|c|c|c|}
\hline Sleep disorder & Clinical features & Diagnostic criteria & Treatment & Proposed pathophysiology \\
\hline $\begin{array}{l}\text { REM sleep behaviour } \\
\text { disorder (RBD) }\end{array}$ & $\begin{array}{l}\text { RBD occurs with loss of normal REM muscle } \\
\text { atonia, resulting in dream enactment, } \\
\text { often with injury to the patient/bed } \\
\text { partner. Events tend to be memorable and } \\
\text { associated with dreams. }\end{array}$ & $\begin{array}{l}\text { Repeated episodes of sleep } \\
\text { vocalisation and/or motor } \\
\text { behaviours documented in } \\
\text { video PSG during REM sleep or } \\
\text { based on clinical history. PSG } \\
\text { demonstrates REM sleep without } \\
\text { atonia. }\end{array}$ & $\begin{array}{l}\text { Melatonin and clonazepam, although } \\
\text { no RCTs to date. }\end{array}$ & $\begin{array}{l}\text { 1. Dysfunction of the subcoeruleus } \\
\text { nucleus, the medullary } \\
\text { magnocellularis and the } \\
\text { sublaterodorsal nucleus } \\
\text { 2. Glutamatergic, GABAergic and } \\
\text { cholinergic abnormalities }\end{array}$ \\
\hline
\end{tabular}

Sleep-related movement disorders

Restless leg syndrome and periodic limb movements during sleep
Unpleasant sensation in the $\mathrm{LL}$, affecting onset and maintenance of sleep. PLMS are periodic, repetitive LL movements typically co-occurring with RLS
RLS: Sensation begins or worsens Dopamine agonists (rotigotine, during periods of rest (eg, lying down), predominantly at night, which are relieved by movements. Symptoms should cause concern, sleep disturbance or impairment in important areas of functioning (eg, physical, social).

PLMS: PSG demonstrates PLMS with a frequency of $>15$ hours and causes significant sleep disturbance or impairs other important areas of functioning. pramipexole, ropinirole), gabapentin and pregabalin
1. Altered spinal circuits in sensory and motor processing areas

2. Dopaminergic and glutamatergic dysfunction

3. Iron deficiency

CPAP, continuous positive airways pressure; CSF, cerebral spinal fluid; GABA, gamma aminobutyric acid; LL, lower Limb; MSLT, multiple sleep latency test; N3, non-rapid eye movement stage 3; NREM, non-rapid eye movement sleep; OSA, obstructive sleep apnoea; PLMS, periodic limb movements during sleep; PSG, polysomnography; QoL, quality of life; RBD, REM sleep behaviour disorder; RCTs, randomised controlled trials; REM, rapid eye movement sleep; RLS, restless leg syndrome; VLPO, ventrolateral preoptic nucleus; VPLO, ventrolateral preoptic area.

disorder after 12 years. ${ }^{6}$ Those patients diagnosed with $\mathrm{PD}$ and RBD tend towards more severe clinical features, including increased motor symptom severity, higher rates of axial symptoms, psychiatric symptoms, hallucinations, autonomic dysfunction, cognitive impairment and impulse control disorders, as well as a generally longer motor disease duration, when compared with PD patients without RBD. ${ }^{7-9}$ Recent imaging studies of those with comorbid PD and RBD demonstrate prominent loss of volume in the pontomesencephalic tegmentum, PPN network dysfunction and reduced signalling in the locus coeruleus compared with those with PD alone. ${ }^{10-12}$

Although often reported, systematic studies of RLS and PLMS have found conflicting results, but with close matching of control populations a general absence of RLS was observed, while use of actigraphy demonstrated high rates of PLMS. Evidence for the pathogenesis of PD and RLS is conflicting, some studies have reported reduced nigrostriatal dopaminergic activity in idiopathic RLS, ${ }^{13}$ while one longitudinal imaging study demonstrated increased dopaminergic transporter availability in both the caudate and putamen to be associated with the presence of RLS. ${ }^{14}$ It is also possible that RLS in PD is related to dopaminergic treatment rather than the disease itself. The prevalence of RLS in de novo PD patients is comparable to controls, with a longitudinal study showing significantly higher rates of RLS at 3 year follow-up than that at baseline in drug naïve patients. ${ }^{15}$ Stimulation of the subthalamic nuclei (STN) has also been shown to increase rates of RLS, with overstimulation of the dopaminergic system thought to resemble the clinical features of augmentation. $^{7}$

Conflicting results have been found for rates of sleep apnoea syndromes (SAS), with some studies identifying comparable apnoea-hypopnea indices (AHI) levels and a comparable risk of OSA and central sleep apnoea (CSA), while elevated AHI have also been reported at higher rates in those with PD compared with controls. ${ }^{16-19}$ However, several of these studies have not identified the typical oxygen desaturation profiles observed with obstructive SAS, as well as the body mass indices of those with PD being significantly lower compared with that of controls. These findings suggest that the sleep disordered breathing identified may represent nocturnal motor involvement of respiratory muscles or a precursor to later stage dysautonomia, rather than the more typical OSA observed in the general population. ${ }^{20}$ Extensive loss of neurons, in particular within respiratory control structures such as the brainstem, may also contribute to respiratory disorders. PD patients show abnormal ventilatory response to hypoxia and hypercapnia suggesting involvement of the medulla, with neuronal and astrocyte reduction in the retrotrapezoid nucleus, nucleus of the solitary tract and pre-Bötzinger complex resulting in abnormal respiratory function in murine models of PD. ${ }^{21}$

Several studies have also reported reduced melatonin secretion in patients, with a case-control study showing a fourfold decrease in circulating melatonin levels in those with $\mathrm{PD}$, and reduced melatonin rhythm amplitude in those with excessive daytime sleepiness. ${ }^{22}$ These circadian disturbances are present in early disease stages and are often associated with cognitive decline and psychiatric disorders. ${ }^{23}$ In addition, reduced expression of Bmal1 (a clock gene) has been found to correlate positively with PD severity and PSQI scores, providing further evidence of a link between circadian rhythm and sleep disturbances. ${ }^{24}$

\section{Sleep disorders related to motor symptoms in PD}

Studies involving PD cohorts $(n=45)$ have shown a positive correlation between PLMS, daytime sleepiness and more severe motor rating scores and reduced mobility. ${ }^{25}$ A number of studies have also established a strong link between $\mathrm{RBD}$ and subsequent neurodegenerative disorders, with retrospective analysis of PSG data ( $\mathrm{n}=59 \mathrm{PD}$ patients) identifying faster motor progression in those with RBD $(n=15)$ and REM sleep without atonia (RWA) $(n=22)$ compared with those with preserved REM sleep atonia $(n=22, p=0.015)$. However, this could also be due to increased disease severity and degeneration associated with RBD in PD patients. ${ }^{26}$ Several studies also implicate cognitive impairment 
Table 2 Case-control polysomnography studies involving patients diagnosed with degenerative movement disorders

\begin{tabular}{|c|c|c|c|c|c|}
\hline Disorder & Author & Year & Cohort & Assessment & Outcome \\
\hline HD & Wiegand et $a l^{95}$ & 1991 & $\begin{array}{l}H D(12) \\
H C(12)\end{array}$ & Two nights of PSG & $\begin{array}{l}\text { Patients had an increased sleep onset latency, reduced sleep efficiency, } \\
\text { increased no of awakenings and reduced slow wave sleep compared with } \\
\text { controls. }\end{array}$ \\
\hline HD & Emser et a $l^{97}$ & 1988 & $\begin{array}{l}\text { HD (10) } \\
\text { HC (12); seven } \\
\text { volunteers }\end{array}$ & Two nights of PSG & $\begin{array}{l}\text { HD and HC had no differences except for two patients who had a reduction } \\
\text { in slow wave sleep. Sleep spindle was also increased during N2 which } \\
\text { correlated to duration of disease. }\end{array}$ \\
\hline HD & Cuturic et $a l^{98}$ & 2009 & $\begin{array}{l}\text { HD (12) } \\
\text { HC (9) }\end{array}$ & One night of PSG, ESS & $\begin{array}{l}\text { ESS score had no significant difference between groups. Sleep latency was } \\
\text { significantly longer in patients. Nocturnal SRBD were absent. }\end{array}$ \\
\hline HD & Goodman et a $/^{99}$ & 2011 & $\begin{array}{l}\text { HD (9) } \\
\text { HC (10) }\end{array}$ & $\begin{array}{l}\text { Three nights v-PSG, MSLT, } \\
\text { ESS, Actigraphy, FOSQ, } \\
\text { MOS, BDI-2 }\end{array}$ & $\begin{array}{l}\text { FOSQ, ESS and MOS scores did not differ from controls. Sleep architecture } \\
\text { (lower percentage of REM sleep) and sleep efficiency differed compared with } \\
\text { controls. }\end{array}$ \\
\hline HD & Piano et $\left.a\right|^{102}$ & 2015 & $\begin{array}{l}\text { HD (30) } \\
\text { HC (30) }\end{array}$ & $\begin{array}{l}1 \text { night v-PSG, ESS, IRLSSG, } \\
\text { BQ, RBDSQ }\end{array}$ & $\begin{array}{l}\text { Two patients reported RLS, } 8 \text { had scores } \geq 9.8 \text { patients had high risk of OSA. } \\
2 \text { had pathological RBD. PSG showed no RWA and RBD. Disease duration } \\
\text { correlated with ESS. }\end{array}$ \\
\hline SCA & Seshagiri et al ${ }^{103}$ & 2018 & $\begin{array}{l}\text { SCA1 (6) SCA2 (5) } \\
\text { SCA3 (7) HC (6) }\end{array}$ & Overnight PSG & Sleep spindle density significantly decreased in SCA. \\
\hline SCA & $\begin{array}{l}\text { Rodríguez-Labrada } \\
\text { et a }\left.\right|^{64}\end{array}$ & 2019 & $\begin{array}{l}\text { SCA2 }(20) \\
\text { SCA2 preclinical carriers } \\
(20) \\
\text { HC }(20)\end{array}$ & One whole night of PSG & $\begin{array}{l}\text { Compared with controls sleep spindle density was significantly reduced } \\
\text { in SCA2 and preclinical patients. Reduced spindle activity correlated with } \\
\text { reduced N3 sleep in SCA2 patients. }\end{array}$ \\
\hline SCA & Rueda et $a^{66}$ & 2016 & $\begin{array}{l}\text { SCA } 6(12) \\
\text { HC (12) }\end{array}$ & Overnight PSG & $\begin{array}{l}\text { SCA6 had higher frequency of snoring, respiratory disorders and slow wave } \\
\text { sleep compared with controls. }\end{array}$ \\
\hline SCA & Pedroso et a ${ }^{65}$ & 2013 & $\begin{array}{l}\text { SCA3 (22) from } 15 \\
\text { families } \\
\text { HC (20) }\end{array}$ & $\begin{array}{l}\text { Overnight PSG, RBDSQ, } \\
\text { IRLSSG }\end{array}$ & $\begin{array}{l}\text { SCA3 patients; } 54 \% \text { had RLS, } 77 \% \text { had PLMS, } 73 \% \text { had RWA and } 59 \% \text { had } \\
\text { RBD. }\end{array}$ \\
\hline SCA & $\begin{array}{l}\text { Velázquez-Pérez } \\
\text { et al }{ }^{04}\end{array}$ & 2011 & $\begin{array}{l}\text { SCA2 (32) } \\
\text { HC (32) }\end{array}$ & $\begin{array}{l}\text { Two nights of v-PSG, ESS, } \\
\text { sleep interviews }\end{array}$ & $\begin{array}{l}\text { Reduced REM sleep percentage and REM density, an increase in RWA, PLMS } \\
\text { in } 37.5 \% \text { of patients. } 21.8 \% \text { complained of insomnia vs } 3 \% \text { in HC and RLS } \\
\text { diagnosed in } 25 \% \text { of patients compared with } 3 \% \text { in HC. No difference in ESS } \\
\text { scores. }\end{array}$ \\
\hline SCA & Silva et $a^{65}$ & 2016 & $\begin{array}{l}\text { SCA3 (47) } \\
\text { HC (47) }\end{array}$ & $\begin{array}{l}\text { Overnight PSG, IRLSSG, } \\
\text { RBDSQ, }\end{array}$ & $\begin{array}{l}\text { SCA3 had higher frequency of arousals from slow wave sleep, parasomnia } \\
\text { complaints, RWA, PLMI, percentage of N1 and N3 sleep. }\end{array}$ \\
\hline SCA & Chi et al ${ }^{105}$ & 2013 & $\begin{array}{l}\text { SCA } 3(15) \\
\text { HC (16) }\end{array}$ & Overnight PSG, ESS & $\begin{array}{l}\text { SCA3 patients had reduced sleep efficiency and percentage of REM sleep } \\
\text { which negatively correlated with severity of ataxia. ESS was normal to } \\
\text { controls. }\end{array}$ \\
\hline SCA & Reimold et al ${ }^{68}$ & 2006 & $\begin{array}{l}\text { SCA1 (10), SCA2 (4) } \\
\text { SCA3 (2), HC (9) }\end{array}$ & Overnight PSG, ESS & $\begin{array}{l}\text { RLS present in } 25 \% \text { of SCA1 and SCA2 patients, } 100 \% \text { of SCA3 patients. All } \\
\text { RLS patients had abnormal PLMS score. One RLS had OSA. } 1 \text { SCA2 and SCA3 } \\
\text { patient had EDS. }\end{array}$ \\
\hline SCA & London et a ${ }^{67}$ & 2018 & $\begin{array}{l}\text { SCA } 10(23) \\
\text { HC (23) }\end{array}$ & One night of PSG, ESS & $\begin{array}{l}\text { SCA10 patients had longer REM sleep and more REM arousal than controls. } \\
\text { REM sleep onset correlated with disease duration. }\end{array}$ \\
\hline WD & Netto et $a l^{106}$ & 2010 & $\begin{array}{l}\text { WD (25) } \\
\text { HC (25) }\end{array}$ & PSG & $\begin{array}{l}\text { Patients had reduced total sleep time, sleep efficiency, percentage of N3 } \\
\text { sleep, and REM sleep, prolonged sleep-onset latency and latency to N2. }\end{array}$ \\
\hline WD & Trindade et $a l^{72}$ & 2017 & $\begin{array}{l}\text { WD (42) } \\
\text { HC (42) }\end{array}$ & $\begin{array}{l}\text { v-PSG, IRLSSG, ESS, PSQI, } \\
\text { BDI }\end{array}$ & $\begin{array}{l}\text { Sleep quality was worse compared with HC. WD patients showed lower sleep } \\
\text { efficiency, less N2 sleep and more WASO and arousal compared with HC. WD } \\
\text { with RLS showed significantly more PLM, more N1 sleep and a longer REM } \\
\text { sleep latency. }\end{array}$ \\
\hline
\end{tabular}




\begin{tabular}{|c|c|c|c|c|c|}
\hline Disorder & Author & Year & Cohort & Assessment & Outcome \\
\hline WD & Tribl et al ${ }^{70}$ & 2015 & $\begin{array}{l}\text { WD (41) } \\
\text { HC (41) }\end{array}$ & $\begin{array}{l}\text { v-PSG, RBDSQ, PSQI, ESS, } \\
\text { MSQ, clinical and sleep } \\
\text { interviews }\end{array}$ & $\begin{array}{l}5 \text { WD patients fulfilled the RBD criteria and had significantly higher values } \\
\text { in RWA. RWA in WD patients without RBD was still significantly increased } \\
\text { compared with controls. }\end{array}$ \\
\hline WD & Nevsimalova et al ${ }^{71}$ & 2011 & $\begin{array}{l}\text { WD (55) } \\
\text { HC (55) }\end{array}$ & $\begin{array}{l}\text { PSG ( } 24 \text { WD and HC), ESS, } \\
\text { RBDSQ, }\end{array}$ & $\begin{array}{l}13 \text { WD patients fulfilled RLS criteria. WD patients were more prone to } \\
\text { daytime napping, EDS and poor nocturnal sleep. Mean ESS and RBDSQ were } \\
\text { higher than controls. TST was lower, with decreased sleep efficiency and } \\
\text { increased wakefulness. WD had lower latency of N1 and N2 sleep. } 14 \% \text { had } \\
\text { MSLT < } 8 \text { min. }\end{array}$ \\
\hline NPC & Vankova et al ${ }^{74}$ & 2003 & $\begin{array}{l}\text { Juvenile NPC (5) } \\
\text { HC (12) }\end{array}$ & $\begin{array}{l}\text { At least one night of PSG, } \\
\text { MSLT }\end{array}$ & $\begin{array}{l}\text { In all patients, sleep was fragmented and disorganised. Total sleep time and } \\
\text { sleep efficiency was lower, shorter sleep latency and increased WASO. }\end{array}$ \\
\hline
\end{tabular}

BDI/-2, Beck's depression inventory; BQ, Berlin Questionnaire; EDS, excessive daytime sleepiness; ESS, Epworth Sleepiness Scale; FOSQ, Functional Outcomes of Sleep Questionnaire; HC, healthy control; HD, Huntington's disease; HDSS, Hungtinton's Disease Sleepiness Scale; IRLSSG, International Restless Leg Syndrome Study Group; MSLT, Multiple Sleep Latency Test; MSQ, Mayo Sleep Questionnaire; NPC, Niemann-Pick disease Type C; OSA, obstructive sleep apneoa; PLMI, Periodic Limb Movement Index; PLMS, periodic limb movement during Sleep; PSG, polysomnography; PSQI, Pittsburgh Sleep Quality Index; RBD, rapid eye movement sleep behaviour disorder; RBDSQ, Rapid Eye Movement sleep Behaviour Disorder Screening Questionnaire; REM, rapid eye movement sleep; RLS, Restless leg syndrome; RWA, rapid eye movement sleep without atonia; SCA, spinocerebellar ataxia; SRBD, sleep-related breathing disorder; v-PSG, video polysomnography; WASO, wake after sleep onset; WD, Wilson's disease.

in the exacerbation of sleep disorders and altered sleep structure. ${ }^{27}$ Patients with PD with primary sleep disorders (RBD and insomnia) had significantly poorer global cognition, visuospatial and executive function in comparison to both unaffected controls and patients with PD without sleep disorders. ${ }^{28}$

\section{Impact of treatment used in the management of motor} symptoms on sleep

Dopaminergic therapy

Night-time akinesia can worsen underlying disturbances to sleep. A placebo-controlled study of controlled release levodopa/carbidopa in patients with PD $(n=40)$ found improved nocturnal akinesia and therefore increased total hours slept, however, immediate release preparations result in reduced total sleep time and lower rates of RBD-related symptoms. ${ }^{17}$ In contrast, several studies have shown that the use of dopamine agonists results in increased levels of nocturnal activity and higher levels of daytime sleepiness compared with levodopa therapy. ${ }^{29}$ Suddenonset sleep is sometimes described in PD and attributed to the sedative effects of dopamine agonists, with these 'sleep attacks' prompting safety concerns, particularly in relation to driving. ${ }^{30}$ However, transdermal rotigotine patches have been shown to effectively aid sleep continuity, sleep stability and REM sleep, with comparable outcomes to pramipexole and superior to treatment with ropinirole. ${ }^{3132}$ Dopamine agonists are also licensed for use in the treatment of RLS and PLMS, however, increasing recognition of impulse control disorder and augmentation as common side effects have limited their use, with pregabalin or gabapentin frequently used as alternatives.

\section{Monoamine oxidase inhibitors}

Rasagiline can be alerting, with fatigue-related questionnaires completed by those with PD showing significant improvements to baseline scores at 12 weeks $(n=16, p=0.003)$. Dopaminenaïve PD patients $(n=1176)$ demonstrated dose-related improvements at week 36 compared with placebo $(1 \mathrm{mg} \mathrm{p}=0.003 ; 2 \mathrm{mg}$ $\mathrm{p}<0.0001)$, while PSG studies show increased sleep maintenance and lower wake after sleep onset (WASO) compared with controls. ${ }^{33}$ Safinamide also improves sleep disorders in PD, likely due to its dual dopaminergic and glutaminergic mechanisms, while amphetamine-like derivatives of selegiline can worsen sleep quality by promoting the onset of insomnia.

\section{Deep brain stimulation}

PSG studies have noted improvements following STN stimulation, with increased total sleep time, decreased WASO $(p<0.05)$ and longer periods of continuous sleep $(p<0.05)$, while PPN stimulation-although experimental and performed in few patients-resulted in increased percentage REM sleep in both PD and PSP populations. ${ }^{34}$ The efficacy of DBS in the management of sleep disorders in PD is conflicting, the majority of studies suggest that DBS has no impact on RBD, ${ }^{35}$ although restoration of RWA has been noted. ${ }^{36}$ Several studies have shown improvement in RLS symptoms following DBS, ${ }^{37} 38$ while one study found that STN-DBS resulted in the emergence of RLS in 19\% of those with PD. ${ }^{7}$

\section{Therapeutics used in the management of sleep disorders in PD}

\section{Wake-promoting agents}

These include stimulants such as modafinil and methylphenidate, used to promote wakefulness in hypersomnolence. A recent meta-analysis demonstrated improvement in subjective sleepiness with modafinil, although no subjective improvement in fatigue or objective measures of sleepiness (MSLT or MWT). ${ }^{39}$ Studies of other agents have also shown promising results with sodium oxybate $\left(\mathrm{GABA}_{\mathrm{B}}\right.$ receptor agonist) decreasing ESS scores and increasing mean sleep latency, while methylphenidate resulted in a significant reduction to fatigue compared with placebo in PD populations. ${ }^{40}$

\section{Melatonin}

Melatonin is produced by the pineal gland with levels rising in darkness and acting as a key regulator of the sleep wake cycle. It has a short half-life at $30-60 \mathrm{~min}$ and is licensed to treat sleep onset insomnia as well as being used off licence to treat RBD with PSG studies showing restoration of REM atonia, with case-control studies suggesting fewer side effects compared with clonazepam. ${ }^{41}$ However, a recent placebo-controlled randomised controlled trial (RCT) found prolonged-release melatonin to have no significant impact on the subjective reporting of RBD symptoms. ${ }^{42}$ Agomelatine, a synthetic melatonin analogue, initially developed for treatment of depression, has also been shown to alleviate sleep disturbances (PLMS and awakenings) in PD. ${ }^{43}$ 


\begin{tabular}{|c|c|c|c|c|c|}
\hline Disorder & Author & Year & Cohort & Assessment & Outcome \\
\hline Dystonia & Gadoth et al $\left.\right|^{107}$ & 1989 & $\begin{array}{l}\text { HPD (3) } \\
\text { HC (11) }\end{array}$ & $\begin{array}{l}\text { PSG over two nights (two } \\
\text { patients, and one night in } \\
\text { one patient and } \mathrm{HC} \text { ) }\end{array}$ & Sleep structure appeared to be normal in all subjects. \\
\hline Dystonia & Jankel et al ${ }^{108}$ & 1983 & $\begin{array}{l}\mathrm{DMD}(4) \\
\mathrm{HC}(4)\end{array}$ & PSG over three nights & $\begin{array}{l}\text { PSG showed increased sleep latency, reduced sleep efficiency and } \\
\text { unusually high voltage of sleep spindles }(>100 \mu \mathrm{V}) \text { sleep spindles during } \\
\text { N2. }\end{array}$ \\
\hline Dystonia & Jankel et al ${ }^{109}$ & 1984 & $\begin{array}{l}\text { DMD (9) } \\
\text { HC (9) }\end{array}$ & PSG over three nights & $\begin{array}{l}\text { All patients slept poorly, patients with advance stages of dystonia } \\
\text { all displayed high-amplitude ( }>150 \mu \mathrm{V}) \text { spindles during } \mathrm{N} 2 \text { and } \mathrm{N} 3 \text {, } \\
\text { increased sleep latency, less REM sleep, increased no of awakenings and } \\
\text { poor sleep efficiency. }\end{array}$ \\
\hline Dystonia & Fish et $a^{110}$ & 1990 & $\begin{array}{l}\text { Primary TD (14) } \\
\text { Secondary TD (10) } \\
\text { Other neurological disorders (39) }\end{array}$ & PSG over two nights & $\begin{array}{l}\text { Four patients (taking benzodiazepines) with TD had increased sleep } \\
\text { spindles more than both control groups. All patients with severe disease } \\
\text { had abnormal sleep spindles. }\end{array}$ \\
\hline
\end{tabular}

\begin{tabular}{|c|c|c|c|c|c|}
\hline Dystonia & Fish et al ${ }^{111}$ & 1991 & $\begin{array}{l}\text { Primary TD (14) } \\
\text { Secondary TD (10) } \\
\text { Other neurological disorders (39) } \\
\text { HC (10) } \\
\text { Same sample as Fish et al., } 1990\end{array}$ & PSG over two nights & $\begin{array}{l}\text { All patients and controls showed reduced EMG activity during REM } \\
\text { sleep compared with wakefulness. Patients with secondary TD had fewer } \\
\text { bursts of activity than normal subjects. RBD was absent in all groups. }\end{array}$ \\
\hline Dystonia & Fish et $a l^{112}$ & 1991 & $\begin{array}{l}\text { Primary TD (14) } \\
\text { Secondary TD (10) } \\
\text { Other neurological disorders (39) } \\
\text { HC (10) } \\
\text { Same sample as Fish et al., } 1990\end{array}$ & PSG over two nights & $\begin{array}{l}\text { Movements were most frequent during awakening, proceeded by } \\
\mathrm{N} 1 \text {, with very few movements during N2 and REM sleep. Sleep- } \\
\text { related movements in primary and secondary TD emerged after brief } \\
\text { awakenings. }\end{array}$ \\
\hline Dystonia & Lobbezoo et al ${ }^{113}$ & 1996 & $\begin{array}{l}\mathrm{CD}(9) \\
\mathrm{HC}(9)\end{array}$ & PSG over two nights & $\begin{array}{l}\text { PSG in CD patient were normal. Sleep was associated with an } \\
\text { improvement of symptoms in CD, with abnormal cervical muscle activity } \\
\text { decreasing immediately when lying down and then being abolished } \\
\text { when transitioning to light NREM sleep. }\end{array}$ \\
\hline Dystonia & $\begin{array}{l}\text { Brüggemann } \\
\text { et al }{ }^{81}\end{array}$ & 2014 & $\begin{array}{l}\text { DRD (23) } \\
\text { HC (26) }\end{array}$ & $\begin{array}{l}\text { PSG over one night, } \\
\text { PSQI, ESS, SSS, FEPS-2, } \\
\text { BDI, self-administered } \\
\text { comorbidity } \\
\text { questionnaire }\end{array}$ & $\begin{array}{l}\text { Sleep quality, SSS and ESS was similar across groups. Six patients } \\
\text { underwent PSG, two had reduced sleep efficiency, two increased sleep } \\
\text { latency, five increased REM latency, four had initiation problems and } \\
\text { four had increased in numbers of arousal. }\end{array}$ \\
\hline $\begin{array}{l}\text { Tic } \\
\text { Disorders }\end{array}$ & $\begin{array}{l}\text { Hashimoto et } \\
\text { al }{ }^{114}\end{array}$ & 1981 & $\begin{array}{l}\text { TS (9) } \\
\text { HC (9) }\end{array}$ & PSG & $\begin{array}{l}\text { At all stages of sleep, body movements during sleep were more frequent } \\
\text { in cases of TS. Twitch movements in REM sleep were significantly } \\
\text { increased in TS. TS patients had increased total sleep time, REM sleep } \\
\text { and NREM sleep. }\end{array}$ \\
\hline $\begin{array}{l}\text { Tic } \\
\text { Disorders }\end{array}$ & $\begin{array}{l}\text { Voderholzer et } \\
\text { al }{ }^{115}\end{array}$ & 1997 & $\begin{array}{l}\text { TS (7) } \\
\text { HC (7) }\end{array}$ & Two nights of PSG & $\begin{array}{l}5 / 7 \text { showed frequent PLMS in NREM and total sleep time significantly } \\
\text { lower in TS group }(p<0.05) \text {. }\end{array}$ \\
\hline $\begin{array}{l}\text { Tic } \\
\text { Disorders }\end{array}$ & Cohrs et al ${ }^{116}$ & 2001 & $\begin{array}{l}\text { TS (25); adults } \\
\text { HC (11) }\end{array}$ & $\begin{array}{l}\text { v-PSG over two } \\
\text { consecutive nights }\end{array}$ & $\begin{array}{l}\text { Patients with TS showed reduced sleep efficiency, total sleep time/ } \\
\text { time in bed, and percentage of slow wave sleep, as well as significantly } \\
\text { prolonged sleep latency, significantly increased percentage of } \mathrm{N1} \text {, } \\
\text { percentage of time awake, and increased number of awakenings and } \\
\text { sleep stage changes/hour sleep period time. }\end{array}$ \\
\hline $\begin{array}{l}\text { Tic } \\
\text { Disorders }\end{array}$ & Kirov et al ${ }^{118}$ & 2007 & $\begin{array}{l}\text { TS+ADHD (19) } \\
\text { HC (19) }\end{array}$ & Two nights of PSG & $\begin{array}{l}\text { Shorter REM sleep latency and increased REM sleep duration in patients } \\
\text { with TS+ADHD. }\end{array}$ \\
\hline $\begin{array}{l}\text { Tic } \\
\text { Disorders }\end{array}$ & Stephens et $a l^{88}$ & 2013 & $\begin{array}{l}\text { TS }(20) \\
\text { TS+ADHD (21) } \\
\text { HC (16) } \\
\text { ADHD (33) }\end{array}$ & $\begin{array}{l}\text { Two nights of } \\
\text { PSG, respiration belt }\end{array}$ & $\begin{array}{l}\text { Total no of leg movements higher in TS+ADHD group compared with } \\
\text { TS only. Children with TS and ADHD had a significant higher number of } \\
\text { arousals from slow wave sleep and total arousals. }\end{array}$ \\
\hline
\end{tabular}




\begin{tabular}{|c|c|c|c|c|c|}
\hline Disorder & Author & Year & Cohort & Assessment & Outcome \\
\hline $\begin{array}{l}\text { Tic } \\
\text { Disorders }\end{array}$ & Kirov et a/ ${ }^{119}$ & 2016 & $\begin{array}{l}\text { TS (21) } \\
\text { ADHD/TS (21) } \\
\text { ADHD (24) } \\
\text { HC (22) }\end{array}$ & Two nights of PSG & $\begin{array}{l}\text { Increased REM sleep and shorted REM latency in children with } \\
\text { psychiatric disorders than controls. }\end{array}$ \\
\hline
\end{tabular}

ADHD, attention-deficit/hyperactivity disorder; BDI, Beck's Depression Inventory; CD, cervical dystonia; DRD, dopamine-responsive dystonia; EMG, electromyography; ESS, Epworth Sleepiness Scale; FEPS-2, Sleep-related Personality Traits Questionnaire; HC, healthy control; HPD, Hereditary Progressive Dystonia; NREM1/2/3, Non-Rapid Eye Movement Sleep stages; PLMS, Periodic Limb Movement during Sleep; PSG, polysomnography; PSQI, Pittsburgh Sleep Quality Index; RBD, Rapid Eye Movement sleep Behaviour Disorder; REM, Rapid Eye Movement Sleep; RLS, Restless leg syndrome; TD, torsion dystonia; TS, Tourette's syndrome; v-PSG, video polysomnography.

\section{Antidepressants and antipsychotics}

Trazodone, a serotonin antagonist and reuptake inhibitor, is licensed for use in the treatment of insomnia in some countries. While there are no studies which evaluate its therapeutic use for sleep disorders within the PD population, effective doses within animal models alleviate dyskinesia and psychosis, but appear to cause sedation. ${ }^{44}$ Other atypical antidepressants including mirtazapine can be effective for insomnia due to potent antihistamine effects but have also been reported to induce or aggravate RBD symptoms in PD cohorts, while use of doxepin in those with PD demonstrated substantial improvements to insomnia, sleep quality and fatigue. Commonly used for the management of hallucinations and delusions, quetiapine, clozapine and pimavenserin are not typically associated with the worsening of motor symptoms in movement disorders. While quetiapine leads to improvements in PD-related psychosis, it has not been shown to impact disturbances to sleep architecture. In contrast, preliminary data relating to pimavanserin (a novel 5-HT2A agonist) suggests improvements to nocturnal symptoms without worsening daytime sedation. ${ }^{45}$ Finally, while there are no RCTs, clonazepam remains widely used in the treatment of RBD, in doses from 0.5 to $2 \mathrm{mg}$, although side effects of sedation at higher doses can be problematic.

\section{Sleep disorders in DLB and the impact of motor disease treatment on sleep}

Fluctuating levels of alertness and REM sleep behaviour disorder form core diagnostic criteria for DLB, while PSG evidence of loss of REM atonia also forms a supportive diagnostic biomarker. RBD in DLB, is often experienced several years before the onset of cognitive decline with PSG studies indicating rates of RBD in DLB to be as high as $71 \%{ }^{46}$ Case-control studies have also identified higher levels of PLMS, with sleep architecture abnormalities evident in $75 \%$, predominantly in the form of RWA (44\%). ${ }^{46}$ Cholinesterase inhibitors (galantamine, donepezil and rivastigmine) used to treat cognitive decline in DLB have been shown to improve sleep quality, reduce fragmented sleep and reduce nocturnal activity. ${ }^{47} 48$

\section{Sleep disorders in MSA}

Sleep disorders are also well documented for MSA. In brief, particularly high rates of RBD are reported (64\%-100\%), with $76 \%(n=21)$ of one study reporting onset prior to their motor symptoms. ${ }^{49}$ Respiratory stridor is also well recognised, as well as being associated with more severe disease progression and sudden death. Case-control studies have identified increased rates of OSA and AHI levels $>5$, compared with controls with continuous positive airways pressure (CPAP) improving stridor and sleep apnoea. ${ }^{50}$ Disruption to subcortical serotonergic neurotransmission is considered to be a key pathophysiological contributor, with depletion of the serotonergic innervation of the raphe nuclei and neurodegeneration of regions involved in respiratory regulation-the brainstem ventral arcuate nucleus and pre-Bötzinger complex cells-considered central in pathogenesis.

\section{REM sleep behaviour disorder in $\alpha$-synuclein disorders}

As outlined above, RBD is a recognised early clinical manifestation among the $\alpha$-synucleinopathies; PD, MSA and DLB, often preceding disease onset by several years and representing a key prodromal marker. ${ }^{51}$ Several imaging studies of those with iRBD have identified changes in multiple brainstem structures, namely the PPN, SLD and LDT region, with those without changes in these regions not observed to later develop PD. ${ }^{52}$

\section{Sleep disorders in PSP}

Studies to date suggest at least $60 \%$ of patients diagnosed with PSP report sleep disturbance, with insomnia being the dominant symptom. RBD and RWA also occur, but at lower rates (5\%-13\%) than that seen in PD, with this not seeming to antedate motor disease onset. ${ }^{53}$ Imaging studies show degeneration of REM-promoting structures, including the PPN and pontine tegmentum, as the likely cause. ${ }^{54} \mathrm{~A}$ recent study also reported that patients diagnosed with PSP with Lewy type alphasynucleinopathy were more frequently diagnosed with probable RBD compared with those with PSP without Lewy pathology. ${ }^{55}$

\section{Sleep disorders in CBS}

Two small PSG studies reported sleep disorders in all of the patients involved, these included PLMS and/or RLS and sleep related breathing disorders including OSA and CSA. Alterations to sleep architecture were also observed, with patients showing decreases in sleep maintenance, total sleep time and RWA. ${ }^{567}$ Although no studies have reported narcolepsy in CBS, there is evidence of reduced hypocretin in cerebral spinal fluid (CSF) compared with those with PD. ${ }^{58}$

\section{Neurodegenerative trinucleotide repeat disorders Sleep disorders in HD}

While sleep disturbance is a frequent complaint, with at least $90 \%$ of carers describing poor sleep, it remains less well characterised due to motor and psychiatric symptoms often dominating, as well as a lack of patient insight. Approximately two-thirds of patient cohorts report insomnia, describing difficulty falling asleep and maintaining sleep, with PSG showing increased sleep fragmentation, decreased $\mathrm{N} 3$ and REM compared with controls. Insomnia is often present early in disease, as well as being reported in premotor manifesting HTT carriers, and increasing with disease progression. ${ }^{59}$ Reduced REM sleep $(n=30)$ has also been shown to be inversely correlated with motor symptom severity $(\mathrm{p}<0.05)$, with cognitive impairment 
also implicated in the exacerbation of sleep disorders and altered sleep structure. ${ }^{27}$

Patients with HD also demonstrate strikingly abnormal circadian rhythms with both a delayed and irregular phase to sleep, with evidence from actigraphy monitoring, as well as abnormal melatonin and cortisol profiles. These changes are also consistently observed in animal models of disease, and are attributed to degeneration of the suprachiasmatic nucleus, hypothalamus and striatum. ${ }^{60} 61$ They can also occur early in the condition and are associated with higher levels of cognitive impairment and anxiety. ${ }^{62}$ Human postmortem studies have shown a loss of orexin-releasing neurons in individuals diagnosed with HD, while transgenic HD mouse models suggest that changes to SCN circuitry are central in driving circadian disruption. ${ }^{60}$

\section{Sleep in relation to the treatment of HD}

Tetrabenazine, a monoamine reuptake inhibitor, is often used in the management of chorea associated with HD although daytime sleepiness is a commonly reported side effect. A study examining the effect of quetiapine (a partial D2 receptor antagonist) in those with HD found amelioration of their symptoms of insomnia, without any worsening of motor function. ${ }^{63}$

\section{Sleep disorders in the SCA}

A broad spectrum of sleep disorders is described among the SCAs, potentially representing widespread brain degeneration beyond the cerebellum. However, technical difficulties exist in measuring REM in those who have developed impaired eye movements and saccades, with this likely accounting for some of the previous reports of abnormal or absent REM sleep. Individuals with SCA2 mutations often report good sleep quality but have abnormal PSG, including reduced N3 sleep and REM sleep. ${ }^{64}$ NREM sleep appears to be the stage most severely affected in those with SCA3 and SCA6 mutations, with increased arousals from slow wave sleep and increased WASO. ${ }^{65}{ }^{66}$ In contrast, a study of SCA10 patients found changes predominantly in REM sleep, including an increased number of REM sleep arousals. ${ }^{67}$

Overall, low rates (0\%-10\%) of PLMS have been noted in those with SCA1 and SCA6 mutations, while higher rates and symptomatic RLS are more often seen in SCA3 cohorts (77\%). ${ }^{66}$ RLS is thought to reflect the basal ganglia involvement, with functional imaging supporting reduced striatal dopamine transporter activity in this region. Further investigation of the postsynaptic dopaminergic system has shown progressive loss of D2 receptors in the caudate, dorsal putamen and ventral striatum. ${ }^{68}$

Sleep-related breathing disorders have been identified in those with SCA2 and SCA6 mutations, including an increased CSA index (events $/ \mathrm{h}=0.97)$ and AHI $(\mathrm{p}=0.022)$ in those with SCA2 mutations, and increased CSA events during sleep $(\mathrm{p}=0.024)$ and oxygen desaturations $(p=0.03)$ in those with SCA6 mutations. ${ }^{66}$ The underlying causative mechanisms remain unknown, although vocal paralysis and dysphonia in combination with neurodegeneration of the supramedullary pathway and brainstem neurons have been proposed. ${ }^{69}$

\section{Sleep disorders in WD and the impact of motor symptom treatment on sleep}

Two video-PSG case-control studies have reported abnormal sleep architecture, with REM stages predominantly affected and a third demonstrating objective daytime sleepiness on MSLT and cataplexylike epsiodes. ${ }^{70}$ There is some limited evidence for higher rates of RLS among those with WD compared with the general population, with $31 \%$ of a single cohort $(n=42)$ meeting diagnostic criteria, and subsequent PSG demonstrating increased PLMS compared with controls $(p=0.009){ }^{72}$ Although in a single case report, D-penicillamine resolved complaints of hypersomnia, while a case-control study identified higher rates of probable RBD found in those treated with D-penicillamine. ${ }^{7173}$

\section{Sleep disorders in NPC}

The heterogeneous and non-specific clinical presentation of NPC challenges its diagnostic process, although secondary cataplexy is an important and discriminatory clinical feature. A single, small $(n=5)$ PSG study has been performed to date, with evidence of reduced total sleep time $(\mathrm{p}<0.01)$, sleep efficiency $(\mathrm{p}<0.001)$, shorter sleep latency $(\mathrm{p}<0.01)$, increased (WASO, $\mathrm{p}<0.05)$ and decreased REM sleep $(\mathrm{p}<0.05) .{ }^{74}$ Reduced CSF hypocretin levels were also observed compared with controls, a feature also seen in narcolepsy and cataplexy, and consistent with hypothalamic dysfunction (figure 2C). ${ }^{74}$

Sleep disorders in anti-IgLON5 and the impact of disease treatment on sleep

IgLON5 is a recently described disorder in which sleep disturbance is pronounced, as well as gait instability and movement disorders. The underlying aetiology of this disorder is thought to be a combination of neuroinflammation and neurodegeneration, with postmortem evidence of hyperphosphorylated tau deposition. ${ }^{75}$ The sleep disorders described include REM and NREM sleep parasomnias, sleep-disordered breathing, namely stridor and obstructive apnoea, insomnia and hypersomnolence. Three PSG studies have identified altered sleep architecture, with evidence of undifferentiated NREM sleep and poorly structured N2 associated with abnormal behavioural manifestations. ${ }^{76-78}$ Treatment of IgLON5 with intravenous steroids show normalised sleep onset and N1 and N2 stages, although marked abnormal sleep reremerged 3 months later in spite of additional immunotherapy. ${ }^{78}$

\section{Sleep disorders in dystonia}

Disturbances to sleep have been reported in 40\%-70\% of dystonia cohorts, with insomnia and abnormal movements during the sleep (eg, RLS) most commonly described, although several studies have also reported few or no disturbances to sleep. ${ }^{79}{ }^{80}$ A probable contributory role of the common psychiatric comorbidities (depression and anxiety in particular) to these sleep-related symptoms, is also likely and important to bear in mind. As such, varying changes in sleep architecture have been observed in distinct types of isolated idiopathic dystonia with PSG recordings of individuals with cervical dystonia $(n=22)$, blepharospasm $(n=3)$, Meige Syndrome $(n=7)$ and in combined genetic forms, such as GCH1 mutation positive doparesponsive dystonia $(n=6)$, showing increased N1 phase (NREM) duration and reduced REM periods, compared with controls. ${ }^{79} 81$

\section{Sleep in relation to the treatment of dystonia}

Levodopa has been shown to benefit sleep in those with GCH1 mutation positive dopa-responsive dystonia, reducing rates of excessive daytime sleepiness, although also reducing total REM sleep. ${ }^{82}$ Trihexyphenidyl has been reported to increase wakefulness and decrease REM sleep, however, the drowsiness experienced at lower doses has limited its clinical use. Benzodiazepines are also often used in the management of dystonia, and as traditional hypnotics they decrease sleep latency but also suppress slow-wave sleep, lengthen REM sleep latency and can cause habituation with rebound insomnia. Also sometimes used, is gabapentin, an alpha 2 delta ligand that increases slow wave sleep, although when used during the day can be associated with drowsiness, fatigue and sedation. However, in children diagnosed with dystonia, gabapentin has been shown to reduce motor symptoms severity $(n=69)$, as well as improve sleep quality and duration $(\mathrm{p}<0.01)$. $^{83}$ 


\section{Sleep disorders in ET}

Sleep disturbances in ET are milder than those seen in PD, with a single PSG-based study showing few objective changes compared with controls, in contrast to those with PD, although examination of the phenotypic heterogeneity among the ET cohort found that those PSG changes observed were most prominent in those with mild cognitive impairment. ${ }^{84} \mathrm{~A}$ recent review, although using questionnaire only data, describes excessive daytime somnolence, RLS, insomnia and nocturia to be frequently reported by patients diagnosed with $\mathrm{ET}^{85}$ Once again, psychiatric comorbidities (anxiety in particular) likely play some role in contributing to the symptoms described.

\section{Sleep in relation to the treatment of ET}

Commonly used in the treatment of ET, beta-blockers often cause or worsen nightmares and restless legs, with 12 studies to date reporting rates of sleep disturbance between $12 \%$ and $60 \% .{ }^{86}$ Primidone has also been reported to have sedative side effects, including daytime sleepiness and tiredness (50\%), often resulting in discontinuation of treatment (27\%). As described above, gabapentin, also sometimes used in the management of tremor, carries with it side effects that include drowsiness, fatigue and sedation.

\section{Sleep in TS}

Many with TS have both insomnia and increased movements at night, during both REM and NREM stages, with studies of those with comorbid attention deficit hyperactivity disorder (ADHD) reporting rates of sleep disorders to be as high as $80 \% .{ }^{87}$ Comparison with healthy controls has shown significant reductions in sleep efficiency $(p<0.05)$ and total sleep time $(p<0.01)$, while sleep latency $(\mathrm{p}<0.05)$ and WASO $(\mathrm{p}<0.001)$ were increased. In contrast, changes to the REM portion of sleep has varied between studies, with some reporting reduced periods $(\mathrm{n}=18 / 34)$, while others show increased or comparable levels to controls. ${ }^{88}$ Other studies have sought to separate TS patients with and without symptoms of ADHD, with reduced REM sleep latency and increased REM sleep observed in both groups, while those with ADHD symptoms also had evidence of insomnia, RLS/PLMS and NREM parasomnias. ${ }^{89}$ Interestingly, variants in the orexin-2/hypocretin-2 (OX2R) receptor gene, mutated in canine narcolepsy, have also been found to be present in those diagnosed with TS. ${ }^{90}$

\section{Sleep in relation to the treatment of TS}

Although in only a small cohort of patients with tics $(n=3)$, abnormal NREM sleep and sleep apnoea resolved in two when treated with tetrabenazine. ${ }^{91}$ A recent review article also noted that those treated with antipsychotics (risperidone, aripiprazole and tiapride) were more likely to experience somnolence, sedation and sleep disturbance. ${ }^{92}$

\section{Challenges in the field}

As outlined above, increasing data suggests sleep disorders to be prevalent across the spectrum of movement disorders, although much of this work is limited by small, heterogenous cohorts. Larger studies often involve questionnaire-based assessments alone, while those that do involve PSG measurements vary in their approach with differences in single night versus multinight assessments. The nightto-night variability typical of all sleep patterns questions the validity of single-night studies, particularly those undertaken in unfamiliar environments. To counter this, portable devices are now widely used in the home setting, allowing longer periods of monitoring. Further work with these non-laboratory-based techniques is needed in order to establish more robust normative values on an individual and disorder-specific level.

While motor symptoms are usually considered as the first cause of sleep disturbance (eg, dystonia in PD), it is important to recognise that comorbidities such as mood disorders and pain also have the potential to impact sleep. The relationship between depression and disturbed sleep is complex and bidirectional, for example, insomnia may be a direct result of depression or secondary to the movement disorder. Although few studies have addressed this issue, some have reported more impaired sleep (sleep maintenance insomnia) in patients with PD and depression than those without depression. Treatment of anxiety and depression should be managed as effectively as possible and may help consolidate the sleep/wake cycle.

Another important area for future understanding, and a potential avenue for therapeutic intervention is the glial-lymphatic glymphatic) pathway, a highly organised fluid transport system moving cerebrospinal fluid (CSF) from the subarachnoid space to the periparenchymal interstitial fluid (ISF). ${ }^{93}$ Murine studies have shown that glymphatic function increases during the sleep, allowing for clearance of metabolic by products. Several studies have demonstrated that during disrupted or impaired sleep, these processes do not have sufficient time for normal clearance, leading to the accumulation of metabolites with subsequent impact on cognition and behaviour. Protein aggregates found in the glymphatic system include alpha-synuclein, as well as amyloid $\beta$ observed in Alzheimer's disease. Dopamine and norepinephrine also appear to contribute to regulating ISF flow within the glymphatic system, resulting in feedforward enhanced neurotransmission increasing dopamine and norepinephrine neurotransmission during wake states. ${ }^{94}$

\section{Assessment and treatment considerations}

A detailed discussion of the management of different sleep disorders is beyond the scope of this review, and only general guidelines are provided. An initial clinical history from both patient and bed partner wherever possible, alongside simple questionnaires, often allows good differentiation of many sleep disorders. Consideration of the impact of motor symptom onset, severity and prescribed medication is also important. Comorbid medical conditions that may cause or contribute to sleep disorders should be considered, for example, primary treatment of psychiatric disorders may improve sleep-related symptoms. Sleep hygiene should be reviewed (eg, caffeine use) and simple behavioural interventions considered in the first instance. Cognitive Behavioural Therapy (CBT) is recommended as standard therapy for the long-term management of insomnia, with digital forms of this treatment becoming increasingly available to broaden access and availability. Pharmacotherapy is effective in the treatment of moderate or severe RLS, with several clear treatment algorithms available, while extensive evidence supports the use of CPAP in the management of OSA, again aided by standardised therapy guidelines.

\section{CONCLUSION}

This review demonstrates that many patients with movement disorders also experience symptoms related to sleep disorders. Dysfunction of the medulla, raphe nuclei, pons and basal ganglia potentially form a shared underlying mechanism for both motor and sleep pathophysiology. For some, there are specific patterns to the sleep problems but for many, changes to sleep are multifactorial, involving medication side effects, motor and non-motor symptoms, suggesting the need for a systematic approach to assessment. Further work is needed to better understand the aetiology of sleep disturbances across distinct movement disorders in order to facilitate more targeted and effective therapeutic strategies, and to understand whether targeting poor sleep leads to clear improvements in motor outcomes. Future 
studies should be directed towards combining limited PSG assessment with far wider application of wearable or mobile home devices in order to identify robust digital biomarkers of utility in diagnosis and symptomatic monitoring.

Acknowledgements Servier Medical Art Images were used in the generation of Figure 2.

Contributors GAB: Conception, acquisition, analysis and interpretation of the data, drafting and revising critically for important intellectual content. EKH: acquisition, analysis and interpretation of the data, drafting and revising critically for important intellectual content. AF: drafting and revising critically for important intellectual content. MAT: drafting and revising critically for important intellectual content. TL: drafting and revising critically for important intellectual content. KNA: Conception, acquisition, analysis and interpretation of the data, drafting and revising critically for important intellectual content. KJP: Conception, acquisition, analysis and interpretation of the data, drafting and revising critically for important intellectual content.

Funding GAB is funded by a KESS2, European Social Fund and Cardiff University PhD Studentship. KJP is funded by an MRC Clinician-Scientist Fellowship (MR/ P008593/1).

\section{Competing interests None declared.}

Patient consent for publication Not required.

Provenance and peer review Not commissioned; externally peer reviewed.

Supplemental material This content has been supplied by the author(s). It has not been vetted by BMJ Publishing Group Limited (BMJ) and may not have been peer-reviewed. Any opinions or recommendations discussed are solely those of the author(s) and are not endorsed by BMJ. BMJ disclaims all liability and responsibility arising from any reliance placed on the content. Where the content includes any translated material, BMJ does not warrant the accuracy and reliability of the translations (including but not limited to local regulations, clinical guidelines, terminology, drug names and drug dosages), and is not responsible for any error and/or omissions arising from translation and adaptation or otherwise.

\section{ORCID iDs}

Grace A Bailey http://orcid.org/0000-0003-4646-3134

Marina AJ Tiissen http://orcid.org/0000-0001-5783-571X

Kathryn J Peall http://orcid.org/0000-0003-4749-4944

\section{REFERENCES}

1 Postuma RB, Berg D. Advances in markers of prodromal Parkinson disease. Nat Rev Neurol 2016:12:622-34.

2 Eichenseer SR, Stebbins GT, Comella CL. Beyond a motor disorder: a prospective evaluation of sleep quality in cervical dystonia. Parkinsonism Relat Disord 2014;20:405-8.

3 Saper CB, Fuller PM. Wake-sleep circuitry: an overview. Curr Opin Neurobiol 2017:44:186-92.

4 Zhang Y, Ren R, Sanford LD, et al. Sleep in Parkinson's disease: a systematic review and meta-analysis of polysomnographic findings. Sleep Med Rev 2020;51:101281.

5 Chahine LM, Amara AW, Videnovic A. A systematic review of the literature on disorders of sleep and wakefulness in Parkinson's disease from 2005 to 2015. Sleep Med Rev 2017;35:33-50.

6 Postuma RB, Iranzo A, Hu M, et al. Risk and predictors of dementia and parkinsonism in idiopathic REM sleep behaviour disorder: a multicentre study. Brain 2019:142:744-59.

7 Marques A, Fantini ML, Morand D, et al. Emergence of restless legs syndrome after subthalamic stimulation in Parkinson's disease: a dopaminergic overstimulation? Sleep Med 2015;16:583-8.

8 Chung SJ, Lee Y, Lee JJ, et al. Rapid eye movement sleep behaviour disorder and striatal dopamine depletion in patients with Parkinson's disease. Eur I Neurol 2017:24:1314-9.

9 Romenets SR, Gagnon J-F, Latreille V, et al. Rapid eye movement sleep behavior disorder and subtypes of Parkinson's disease. Mov Disord 2012:27:996-1003.

10 Gallea C, Ewenczyk C, Degos B, et al. Pedunculopontine network dysfunction in Parkinson's disease with postural control and sleep disorders. Mov Disord 2017:32:693-704.

11 Boucetta S, Salimi A, Dadar M, et al. Structural Brain Alterations Associated with Rapid Eye Movement Sleep Behavior Disorder in Parkinson's Disease. Sci Rep 2016:6:1-11.

12 García-Lorenzo D, Longo-Dos Santos C, Ewenczyk C, et al. The coeruleus/ subcoeruleus complex in rapid eye movement sleep behaviour disorders in Parkinson's disease. Brain 2013:136:2120-9.

13 Earley $\mathrm{CJ}$, Kuwabara $\mathrm{H}$, Wong DF, et al. The dopamine transporter is decreased in the striatum of subjects with restless legs syndrome. Sleep 2011;34:341-7.
14 Moccia M, Erro R, Picillo M, et al. A four-year longitudinal study on restless legs syndrome in Parkinson disease. Sleep 2016;39:405-12.

15 Marchesi E, Negrotti A, Angelini M, et al. A prospective study of the cumulative incidence and course of restless legs syndrome in de novo patients with Parkinson's disease during chronic dopaminergic therapy. J Neurol 2016;263:441-7.

16 Trotti LM, Bliwise DL. No increased risk of obstructive sleep apnea in Parkinson's disease. Mov Disord 2010;25:2246-9.

17 Yong M-H, Fook-Chong S, Pavanni R, et al. Case control polysomnographic studies of sleep disorders in Parkinson's disease. PLoS One 2011;6:e22511.

18 Crosta F, Desideri G, Marini C. Obstructive sleep apnea syndrome in Parkinson's disease and other Parkinsonisms. Funct Neurol 2017:32:137-41.

19 juan MZ, chan LC, qiong JS. Clinical characteristics of sleep disorders in patients with Parkinson's disease. J Huazhong Univ Sci Technol - Med Sci 2017;37:100-4.

20 Diederich NJ, Vaillant M, Leischen M, et al. Sleep apnea syndrome in Parkinson's disease. A case-control study in 49 patients. Mov Disord 2005;20:1413-8.

21 Fernandes-Junior SA, Carvalho KS, Moreira TS, et al. Correlation between neuroanatomical and functional respiratory changes observed in an experimental model of Parkinson's disease. Exp Physiol 2018;103:1377-89.

22 Videnovic A, Noble C, Reid KJ, et al. Circadian melatonin rhythm and excessive daytime sleepiness in Parkinson disease. JAMA Neurol 2014;71:463-9.

23 Breen DP, Vuono R, Nawarathna U, et al. Sleep and circadian rhythm regulation in early Parkinson disease. JAMA Neurol 2014;71:589-95.

24 Cai Y, Liu S, Sothern RB, et al. Expression of clock genes Per1 and BMAL1 in total leukocytes in health and Parkinson's disease. Eur J Neurol 2010;17:550-4.

25 Valko PO, Waldvogel $\mathrm{D}$, Weller $\mathrm{M}$, et al. Fatigue and excessive daytime sleepiness in idiopathic Parkinson's disease differently correlate with motor symptoms, depression and dopaminergic treatment. Eur J Neurol 2010;17:1428-36.

26 Sommerauer M, Valko PO, Werth E, et al. Revisiting the impact of REM sleep behavior disorder on motor progression in Parkinson's disease. Park Relat Disord 2014:20:460-2

27 Aziz NA, Anguelova GV, Marinus J, et al. Sleep and circadian rhythm alterations correlate with depression and cognitive impairment in Huntington's disease. Parkinsonism Relat Disord 2010;16:345-50.

28 Huang J, Zhuo W, Zhang Y. Cognitive function characteristics of Parkinson's disease with sleep disorders. Parkinsons Dis 2017:2017.

29 Comella CL, Morrissey M, Janko K. Nocturnal activity with nighttime pergolide in Parkinson disease: a controlled study using actigraphy. Neurology 2005;64:1450-1.

30 Hobson DE, Lang AE, Martin WRW, Wayne Martin WR, et al. Excessive daytime sleepiness and sudden-onset sleep in Parkinson disease: a survey by the Canadian movement disorders group. JAMA 2002;287:455-63.

31 Poewe WH, Rascol 0, Quinn N, et al. Efficacy of pramipexole and transdermal rotigotine in advanced Parkinson's disease: a double-blind, double-dummy, randomised controlled trial. Lancet Neurol 2007;6:513-20.

32 Mizuno Y, Nomoto M, Hasegawa K. Rotigotine vs ropinirole in advanced stage Parkinson's disease: Adouble-blind study. Park Relat Disord 2014;20:1388-93.

33 Schrempf W, Fauser M, Wienecke M, et al. Rasagiline improves polysomnographic sleep parameters in patients with Parkinson's disease: a double-blind, baselinecontrolled trial. Eur J Neurol 2018:25:672-9.

34 Lim AS, Moro E, Lozano AM, et al. Selective enhancement of rapid eye movement sleep by deep brain stimulation of the human pons. Ann Neurol 2009:66:110-4

35 Cavalloni F, Debove I, Lachenmayer ML, et al. A case series and systematic review of rapid eye movement sleep behavior disorder outcome after deep brain stimulation in Parkinson's disease. Sleep Med 2020;77:170-6.

36 Nishida N, Murakami T, Kadoh K, et al. Subthalamic nucleus deep brain stimulation restores normal rapid eye movement sleep in Parkinson's disease. Mov Disord 2011;26:2418-22.

37 Klepitskaya O, Liu Y, Sharma S, et al. Deep brain stimulation improves restless legs syndrome in patients with Parkinson disease. Neurology 2018;91:e1013-21.

38 Chahine LM, Ahmed A, Sun Z. Effects of STN DBS for Parkinson's disease on restless legs syndrome and other sleep-related measures. Park Relat Disord 2011:17:208-11.

39 Rodrigues TM, Caldas AC, Ferreira JJ. Pharmacological interventions for daytime sleepiness and sleep disorders in Parkinson's disease: Systematic review and metaanalysis. Park Relat Disord 2016;27:25-34.

40 Mendonça DA, Menezes K, Jog MS. Methylphenidate improves fatigue scores in Parkinson disease: a randomized controlled trial. Mov Disord 2007:22:2070-6.

41 Kunz D, Mahlberg R, A two-part MR. A two-part, double-blind, placebo-controlled trial of exogenous melatonin in REM sleep behaviour disorder. J Sleep Res 2010;19:591-6

42 Gilat M, Coeytaux Jackson A, Marshall NS, et al. Melatonin for rapid eye movement sleep behavior disorder in Parkinson's disease: a randomised controlled trial. Mov Disord 2020:35:344-9.

43 Avila A, Cardona X, Martin-Baranera M, et al. Agomelatine for depression in Parkinson disease: additional effect on sleep and motor dysfunction. J Clin Psychopharmacol 2015:35:719-23.

44 Halliday M, Radford H, Zents KAM, et al. Repurposed drugs targeting elF2\&alpha; P-mediated translational repression prevent neurodegeneration in mice. Brain 2017; 140:1768-83. 
45 Patel N, LeWitt P, Neikrug AB, et al. Nighttime sleep and daytime sleepiness improved with Pimavanserin during treatment of Parkinson's disease psychosis. Clin Neuropharmacol 2018;41:210-5

46 Fernández-Arcos A, Morenas-Rodríguez E, Santamaria J, et al. Clinical and videopolysomnographic analysis of rapid eye movement sleep behavior disorder and other sleep disturbances in dementia with Lewy bodies. Sleep 2019;42:1-18.

47 Edwards K, Royall D, Hershey L, et al. Efficacy and safety of galantamine in patients with dementia with Lewy bodies: a 24-week open-label study. Dement Geriatr Cogn Disord 2007;23:401-5.

48 Kazui $\mathrm{H}$, Adachi $\mathrm{H}$, Kanemoto $\mathrm{H}$, et al. Effects of donepezil on sleep disturbances in patients with dementia with Lewy bodies: an open-label study with actigraphy. Psychiatry Res 2017;251:312-8.

49 De Cock VC, Debs R, Oudiette D, et al. The improvement of movement and speech during rapid eye movement sleep behaviour disorder in multiple system atrophy. Brain 2011:134:856-62.

50 Rekik S, Martin F, Dodet P, et al. Stridor combined with other sleep breathing disorders in multiple system atrophy: a tailored treatment? Sleep Med 2018;42:53-60.

51 Iranzo A, Fernández-Arcos A, Tolosa E, et al. Neurodegenerative disorder risk in idiopathic REM sleep behavior disorder: study in 174 patients. PLoS One 2014;9:e89741.

52 Iranzo A, Lomeña F, Stockner H, et al. Decreased striatal dopamine transporter uptake and substantia nigra hyperechogenicity as risk markers of synucleinopathy in patients with idiopathic rapid-eye-movement sleep behaviour disorder: a prospective study [corrected]. Lancet Neurol 2010;9:1070-7.

53 Sixel-Döring F, Schweitzer M, Mollenhauer B, et al. Polysomnographic findings, videobased sleep analysis and sleep perception in progressive supranuclear palsy. Sleep Med 2009:10:407-15.

54 Pyatigorskaya N, Yahia-Cherif L, Gaurav R, et al. Multimodal magnetic resonance imaging quantification of brain changes in progressive supranuclear palsy. Mov Disord 2020;35:161-70.

55 Shprecher DR, Adler CH, Zhang N, et al. Predicting alpha-synuclein pathology by REM sleep behavior disorder diagnosis. Parkinsonism Relat Disord 2018;55:92-6.

56 Roche S, Jacquesson J-M, Destée A, et al. Sleep and vigilance in corticobasal degeneration: a descriptive study. Neurophysio/ Clin 2007;37:261-4.

57 Iriarte J, Alegre M, Arbizu J, et al. Unilateral periodic limb movements during sleep in corticobasal degeneration. Mov Disord 2001;16:1180-3.

58 Yasui K, Inoue Y, Kanbayashi T, et al. Csf orexin levels of Parkinson's disease, dementia with Lewy bodies, progressive supranuclear palsy and corticobasal degeneration. J Neuro/ Sci 2006;250:120-3.

59 Arnulf I, Nielsen J, Lohmann E, et al. Rapid eye movement sleep disturbances in Huntington disease. Arch Neurol 2008;65:482-8.

60 Cabanas M, Pistono C, Puygrenier L, et al. Neurophysiological and behavioral effects of Anti-Orexinergic treatments in a mouse model of Huntington's disease. Neurotherapeutics 2019;16:784-96.

61 Morton AJ, Wood NI, Hastings MH, et al. Disintegration of the sleep-wake cycle and circadian timing in Huntington's disease. J Neurosci 2005;25:157-63.

62 Diago EB, Martínez-Horta S, Lasaosa SS, et al. Circadian rhythm, cognition, and mood disorders in Huntington's disease. J Huntingtons Dis 2018;7:193-8.

63 Alpay M, Koroshetz WJ. Quetiapine in the treatment of behavioral disturbances in patients with Huntington's disease. Psychosomatics 2006;47:70-2.

64 Rodríguez-Labrada R, Galicia-Polo L, Canales-Ochoa N, et al. Sleep spindles and $\mathrm{K}$-complex activities are decreased in spinocerebellar ataxia type 2: relationship to memory and motor performances. Sleep Med 2019;60:188-96.

65 Silva GMF, Pedroso JL, Dos Santos DF, et al. Nrem-Related parasomnias in Machado-Joseph disease: clinical and polysomnographic evaluation. J Sleep Res 2016:25:11-15.

66 Rueda AD, Pedroso JL, Truksinas E, et al. Polysomnography findings in spinocerebellar ataxia type 6. J Sleep Res 2016;25:720-3.

67 London E, Camargo CHF, Zanatta A, et al. Sleep disorders in spinocerebellar ataxia type 10. J Sleep Res 2018;27:e12688.

68 Reimold M, Globas C, Gleichmann M. Spinocerebellar Ataxia Type 1, 2, and 3 and Restless Legs Syndrome: Striatal Dopamine D2 Receptor Status Investigated by [ 11 C]. Raclopride Positron Emission Tomography. 2006.

69 Folha Santos FA, de Carvalho LBC, Prado LFdo, et al. Sleep apnea in MachadoJoseph disease: a clinical and polysomnographic evaluation. Sleep Med 2018;48:23-6

70 Tribl GG, Bor-Seng-Shu E, Trindade MC, et al. Wilson's disease presenting as rapid eye movement sleep behavior disorder: a possible window to early treatment. Arq Neuropsiquiatr 2014:72:653-8.

71 Nevsimalova S, Buskova J, Bruha R, et al. Sleep disorders in Wilson's disease. Eur J Neurol 2011;18:184-90.

72 Trindade MC, Bittencourt T, Lorenzi-Filho G, et al. Restless legs syndrome in Wilson's disease: frequency, characteristics, and mimics. Acta Neurol Scand 2017:135:211-8.

73 Firneisz G, Szalay F, Halasz P, et al. Hypersomnia in Wilson's disease: an unusual symptom in an unusual case. Acta Neurol Scand 2000;101:286-7.

74 Vankova J, Stepanova I, Jech R, et al. Sleep disturbances and hypocretin deficiency in Niemann-Pick disease type C. Sleep 2003;26:427-30
75 Gelpi E, Höftberger R, Graus F, et al. Neuropathological criteria of anti-IgLON5related tauopathy. Acta Neuropathol 2016;132:531-43.

76 Gaig C, Graus F, Compta Y, et al. Clinical manifestations of the anti-IgLON5 disease. Neurology 2017:88:1736-43.

77 Sabater L, Gaig C, Gelpi E, et al. A novel non-rapid-eye movement and rapid-eyemovement parasomnia with sleep breathing disorder associated with antibodies to IgLON5: a case series, characterisation of the antigen, and post-mortem study. Lancet Neurol 2014;13:575-86.

78 Gaig C, Iranzo A, Cajochen C, et al. Characterization of the sleep disorder of antiIgLON5 disease. Sleep 2019:42:1-18.

79 Antelmi E, Ferri R, Provini F, et al. Modulation of the muscle activity during sleep in cervical dystonia. Sleep 2017:40. doi:10.1093/sleep/zsx088. [Epub ahead of print: $01 \mathrm{Jul}$ 2017].

80 Yang J, Shao N, Song W, et al. Nonmotor symptoms in primary adult-onset cervical dystonia and blepharospasm. Brain Behav 2017;7:e00592.

81 Brüggemann N, Stiller S, Tadic V, et al. Non-Motor phenotype of dopa-responsive dystonia and quality of life assessment. Parkinsonism Relat Disord 2014;20:428-31.

82 Van Hove JLK, Steyaert J, Matthijs G, et al. Expanded motor and psychiatric phenotype in autosomal dominant Segawa syndrome due to GTP cyclohydrolase deficiency. J Neurol Neurosurg Psychiatry 2006;77:18-23.

83 Liow NY-K, Gimeno H, Lumsden DE, et al. Gabapentin can significantly improve dystonia severity and quality of life in children. Eur J Paediatr Neurol 2016;20:100-7

84 Rohl B, Collins K, Morgan S, et al. Daytime sleepiness and nighttime sleep quality across the full spectrum of cognitive presentations in essential tremor. J Neurol SCi 2016:371:24-31.

85 Jiménez-Jiménez FJ, Alonso-Navarro H, García-Martín E, et al. Sleep disorders in essential tremor: systematic review and meta-analysis. Sleep 2020;2020:1-11.

86 Morrison I, Frangulyan R, Riha RL. Beta-Blockers as a cause of violent rapid eye movement sleep behavior disorder: a poorly recognized but common cause of violent parasomnias. Am J Med 2011;124:e11.

87 Hibberd C, Charman T, Bhatoa RS, et al. Sleep difficulties in children with Tourette syndrome and chronic tic disorders: a systematic review of characteristics and associated factors. Sleep 2020;43. doi:10.1093/sleep/zsz308

88 Stephens RJ, Chung SA, Jovanovic D, et al. Relationship between polysomnographic sleep architecture and behavior in medication-free children with Ts, ADHD, Ts and ADHD, and controls. J Dev Behav Pediatr 2013:34:688-96.

89 Kirov R, Kinkelbur J, Banaschewski T, et al. Sleep patterns in children with attentiondeficit/hyperactivity disorder, tic disorder, and comorbidity. J Child Psychol Psychiatry 2007:48:561-70

90 Thompson MD, Comings DE, Abu-Ghazalah R, et al. Variants of the orexin2/hcrt2 receptor gene identified in patients with excessive daytime sleepiness and patients with Tourette's syndrome comorbidity. Am J Med Genet B Neuropsychiatr Genet 2004;129B:69-75.

91 Jankovic J, Glaze DG, Frost JD. Effect of tetrabenazine on tics and sleep of Gilles de la Tourette's syndrome. Neurology 1984;34:688-92.

92 Pringsheim T, Holler-Managan Y, Okun MS, et al. Comprehensive systematic review summary: treatment of tics in people with Tourette syndrome and chronic tic disorders. Neurology 2019;92:907-15.

93 Ringstad G, Valnes LM, Dale AM, et al. Brain-Wide glymphatic enhancement and clearance in humans assessed with MRI. JCI Insight 2018;3. doi:10.1172/jci. insight.121537. [Epub ahead of print: 12 Jul 2018].

94 Jennings A, Rusakov DA. Do astrocytes respond to dopamine? Opera Medica Physiol 2016:2:34-43.

95 Wiegand M, Möller AA, Schreiber W, et al. Brain morphology and sleep EEG in patients with Huntington's disease. Eur Arch Psychiatry Clin NeurosCi 1991:240:148-52.

96 Wiegand M, Möller AA, Lauer CJ, et al. Nocturnal sleep in Huntington's disease. J Neurol 1991:238:203-8. doi:10.1007/BF00314781

97 Emser W, Brenner M, Stober T, et al. Changes in nocturnal sleep in Huntington's and Parkinson's disease. J Neurol 1988;235:177-9.

98 Cuturic M, Abramson RK, Vallini D, et al. Sleep patterns in patients with Huntington's disease and their unaffected first-degree relatives: a brief report. Behav Sleep Med 2009:7:245-54

99 Goodman AOG, Rogers L, Pilsworth S, et al. Asymptomatic sleep abnormalities are a common early feature in patients with Huntington's disease. Curr Neurol Neurosci Rep 2011;11:211-7

100 Neutel D, Tchikviladzé M, Charles P, et al. Nocturnal agitation in Huntington disease is caused by arousal-related abnormal movements rather than by rapid eye movement sleep behavior disorder. Sleep Med 2015:16:754-9.

101 Lazar AS, Panin F, Goodman AOG, et al. Sleep deficits but no metabolic deficits in premanifest Huntington's disease. Ann Neurol 2015;78:630-48.

102 Piano C, Losurdo A, Della Marca G, et al. Polysomnographic findings and clinical correlates in Huntington disease: a cross-sectional cohort study. Sleep 2015:38:1489-95.

103 Seshagiri DV, Botta R, Sasidharan A, et al. Assessment of sleep spindle density among genetically positive spinocerebellar ataxias types 1, 2, and 3 patients. Ann Neurosci 2018;25:106-11. 
104 Velázquez-Pérez L, Voss U, Rodríguez-Labrada R, et al. Sleep disorders in spinocerebellar ataxia type 2 patients. Neurodegener Dis 2011;8:447-54.

105 Chi N-F, Shiao G-M, Ku H-L, et al. Sleep disruption in spinocerebellar ataxia type 3: a genetic and polysomnographic study. J Chin Med Assoc 2013;76:25-30.

106 Netto AB, Sinha S, Taly AB, et al. Sleep in Wilson's disease: a polysomnography-based study. Neurol India 2010;58:933-41.

107 Gadoth N, Costeff H, Harel S, et al. Motor abnormalities during sleep in patients with childhood hereditary progressive dystonia, and their unaffected family members. Sleep 1989;12:233-8.

108 Jankel WR, Allen RP, Niedermeyer E, et al. Polysomnographic findings in dystonia musculorum deformans. Sleep 1983;6:281-5.

109 Jankel WR, Niedermeyer E, Graf M, et al. Polysomnography of torsion dystonia. Arch Neurol 1984;41:1081-3.

110 Fish DR, Allen PJ, Sawyers D, et al. Sleep spindles in torsion dystonia. Arch Neurol 1990;47:216-8.

111 Fish DR, Sawyers D, Smith SJ, et al. Motor inhibition from the brainstem is normal in torsion dystonia during REM sleep. J Neurol Neurosurg Psychiatry 1991;54:140-4.

112 Fish DR, Sawyers D, Allen PJ, et al. The effect of sleep on the dyskinetic movements of Parkinson's disease, Gilles de la Tourette syndrome, Huntington's disease, and torsion dystonia. Arch Neurol 1991;48:210-4.
113 Lobbezoo F, Thu Thon M, Rémillard G, et al. Relationship between sleep, neck muscle activity, and pain in cervical dystonia. Can J Neuro/ Sci 1996;23:285-90.

114 Hashimoto T, Endo S, Fukuda K, et al. Increased body movements during sleep in Gilles de la Tourette syndrome. Brain Dev 1981;3:31-5.

115 Voderholzer U, Müller N, Haag C, et al. Periodic limb movements during sleep are a frequent finding in patients with Gilles de la Tourette's syndrome. J Neurol 1997;244:521-6

116 Cohrs S, Rasch T, Altmeyer S, et al. Decreased sleep quality and increased sleep related movements in patients with Tourette's syndrome. J Neurol Neurosurg Psychiatry 2001;70:192-7.

117 Kostanecka-Endress T, Banaschewski T, Kinkelbur J, et al. Disturbed sleep in children with Tourette syndrome: a polysomnographic study. J Psychosom Res 2003:55:23-32.

118 Kirov R, Banaschewski T, Uebel H, et al. REM-sleep alterations in children with co-existence of tic disorders and attention-deficit/hyperactivity disorder: impact of hypermotor symptoms. Eur Child Adolesc Psychiatry 2007;16 Suppl $1: 45-50$.

119 Kirov R, Brand S, Banaschewski T, et al. Opposite impact of REM sleep on neurobehavioral functioning in children with common psychiatric disorders compared to typically developing children. Front Psychol 2016;7:2059. 